\title{
How Fashion Luxury Brands Innovate Marketing Strategies in the Development of Internet Media
}

\author{
Yalei Wang* \\ Department of Hefei 168 Middle School, Hefei, China \\ *Corresponding author: guanghua.ren@gecacdemy.can
}

\begin{abstract}
The development of Internet media has a great influence on the online marketing strategies of fashion luxury brands. Dior, as an online development strategy for a fashion luxury brand, makes a strategy that adapts to the current situation. The purpose of this study was to explore how fashion luxury brands innovate marketing strategies in the development of Internet media. This paper used consumer purchase intention and marketing mix theory. Later, the study used swot analysis method to study the strength, weaknesses, opportunities, and threats of the research object Dior in the online development of fashion luxury brands. This research concluded that Dior's new development strategy for Internet media has achieved current success in the online direction of fashion luxury brands. Based on the discussion of this paper, as well as under the development of Internet media, Dior should continuously optimize online marketing strategies in response to changes in the market environment for the long-term development of brand online sales.
\end{abstract}

Keywords: Luxury Brands, Online, Social Media, Digital Market

\section{Introduction}

Since the rapid development of the Internet in the 21 st century around the world, the publicity and marketing of online social platforms, and the formation of e-commerce platform sales models in the last ten years, online marketing has become a trend for brands to rapidly expand their visibility and influence. In the context of the in-depth integration of the Internet and economic globalization, major changes have taken place in global trade formats, and a new shopping model of "digital trade" represented by e-commerce has gradually formed and continued to expand. Nowadays, the Internet has become the most basic tool for shopping. The Internet has broken geographical boundaries, covered most people, and greatly expanded the number of consumers and different types of groups.

Due to the epidemic, a large number of luxury goods users have opened online purchases, which inadvertently expanded the entire online luxury market. The impact of the epidemic in 2020 has caused a major blow to many industries, and the luxury industry is no exception. The spread of the epidemic has dealt a serious blow to the luxury goods industry, but it has also brought huge opportunities. Affected by the epidemic, offline channel break, luxury goods have moved to the front line, and many online official flagship stores are also available.

There have been many research reports on luxury marketing, Internet development, or sales models, but this article is more willing to explore the possible direct cooperation and influence between them. While most people

Y. W. is with the International Department of Hefei 168 Middle School (e-mail: guanghua.ren@gecacdemy.can)

are still studying the traditional offline sales model, online

platforms have emerged and are accepted by most. The online sales model is fast and convenient, which greatly promotes the increase in sales and increases customer satisfaction.

However, this article will study and show how to use online media to develop new markets in the era of rapid Internet development, especially in the luxury goods industry. Although many luxury goods still attach great importance to the development of offline retail stores, because this is a way to maintain the high-end status of luxury brands and high-quality services. Luxury fashion has won a place in the digital world. Most brands now interact with consumers through their own branded online stores and mufti-brand e-retailers. Although pure online transactions currently account for only a small part of the entire luxury market, this situation will not last long. Nearly half of luxury purchase 
decisions have been influenced by what consumers can see online, and more and more online luxury customers are increasing. Based on the above phenomenon, I want to study and put forward a topic: How are fashion luxury brands innovating marketing strategies on the Internet?

The role of digital technology in service encounters has evolved considerably leading to an emerging understanding of service encounters as mufti-faceted inter- actions involving multiple actors. While more and more businesses realize the importance of multidimensional interactions and are eager to embrace digitization, although the field of luxury has been slow to adopt both digitization and a mufti-actor view. This is understandable as luxury brands thrive on their heritage and often remain cautious about change. Many luxury brands successfully use social media for brand building [1]. This is because the development of online platforms has brought benefits to many luxury brands in terms of sales models and customer base expansion. I just wanted to study what factors in social media directly or indirectly affect the changes in famous brands and consumer behavior. This is very important for how luxury brands will form a stable and creative online sales model in the future. Based on various data and analysis of environmental factors in today's society, the Internet' s new media sales model will enable the sales of luxury brands to have a more rapid and long-term development. This article will explore through qualitative analysis methods such as swot, and summarize its results and impact.

\section{Literature Review}

\subsection{Consumer Purchase Intention}

In the worst competitive market, the consumer products manufacturing industries pay attention to customer purchase intention to maintain their repute in the market and enhance their goodwill [1]. Purchase intention is a kind of decision-making that studies the reason to buy a particular brand by consumer define purchase intention as a situation where consumer tends to buy a certain product in a certain condition. The customer's purchase decision is a complex process. Purchase intention usually is related to the behavior, perceptions, and attitudes of consumers. Purchase behavior is a key point for consumers to access and evaluate the specific product [2]. In previous studies, brand name, product quantity, product packaging, and product price are all the influencing factors of consumer purchase intention. The fast-paced integration of the Internet as a marketing tool in recent years has had a huge impact on how brands chose to communicate with their customers. The Internet has provided a huge platform for local and global brands to expand their market and acquire more customers than ever before. An increasing number of consumers are embracing the internet and spending more time searching for information, which largely affects their purchase intentions. Given such opportunities, firms and their brands have dived into social media marketing, which emerged as the most popular and effective tool of marketing and communication [3]. As a luxury brand that prioritizes online media, Dior's s online marketing and online shopping platforms have gradually matured.

\subsection{Marketing Mix}

Marketing mix means the product, distribution, promotion, and pricing strategies to produce and carry out exchanges and achieve the target markets [4].

The marketing mix management paradigm has dominated marketing since the 1940s and McCarthy (1964) further developed this idea and refined the principle to what is generally known today as the 4Ps. However, in the post-dot-com boom, marketing managers are learning to cope with a whole host of new marketing elements that have emerged from the online world of the Internet [5]. In some ways, these new marketing elements have close analogs in the off-line world, and yet from another perspective, they are revolutionary and worthy of a new characterization into what we coin as the E-Marketing mix (or the e-marketing delta to the traditional marketing mix) [6]. 
Product is defined as a physical product or service to the consumer for which he is willing to pay [4]. It includes half of the material goods, such as furniture, clothing, and grocery items, and intangible products, such as services, which users buy [4].

Price is one of the most important marketing mix items and many scientists consider the price as one of the most important elements of the market, which increases not only profits but also market share [4]. However, the price is not only one of the key factors in a competitive situation, which directly affects the company's sales and profitability indicators, but also one of the most flexible marketing mix elements, which can quickly adapt to environmental changes [4]. Price is the only element of marketing revenue, There is always such an invariable theorem in the market: the lower the price, the higher the sales volume

Place used to be not so important in the marketing mix theory. However, due to the fast development of technology, The emergence of diversified sales channels, especially the most popular $\mathrm{O} 2 \mathrm{O}$ sales form, gives different consumers more places to buy. While expanding sales methods, new markets are constantly emerging through "place".

The last 4P marketing complex element of the promotion, which helps to increase consumer awareness in terms of their products, leads to higher sales, and helps to build brand loyalty [4]. Promotion is a tool in the marketing mix, the purpose of which is to encourage consumers to buy products by disseminating information while enhancing the spread of products and services. Of course, a good marketing first order is also conducive to improving the popularity of products and customer loyalty, "sponsorship" is one of the most effective. The most common marketing means are advertising, promotion, personal sales, public relations and direct marketing [4].

\section{Method}

\subsection{Research Design}

This article adopts a qualitative analysis method. Take Dior as the research object to explore the influence of Internet media on luxury brands and brand marketing plans. In addition, the swot analysis is used for finding out the answer.

\subsection{About Dior}

Dior was founded by Christian Dior on Avenue Montaigne in Paris, France in 1946. The history of Dior is also referred to by some as the chronicle of modern fashion. As one of the important brands that make Paris known as the fashion capital, Dior 's influence in the fashion industry cannot be ignored, and it is also one of the most famous fashion luxury brands today. Its scope of business in the fashion field includes men's and women's handbags, clothing, shoes, jewelry, perfumes, and cosmetics. In the past two years, driven by the strategy of the entire LVMH group, Dior has also formulated a new development strategy. In the use of social media marketing, Dior can even be said to be a "pioneer" in the luxury goods industry. According to the latest report from Morgan Stanley, Dior became the sixth brand in the luxury goods industry with annual sales of more than 5 billion euros in 2018, reaching 5.52 billion euros [7]. As early as 2019, a report released by Launch Metrics pointed out that the total media influence of Paris Fashion Week that year was 129 million US dollars, and the total participation was 42.2 million [7]. If search for "Dior" on the browser, the first search result must be Dior's official online shopping platform. In recent years, in the field of digital marketing that continues to introduce new ones, Dior has quickly grasped the latest market trends. Dior also continues to establish a pioneering image in the digital marketing of fashion luxury brands.

\subsection{SWOT Analysis}

\subsubsection{Strength}

Dior as a famous French luxury brand, Dior's products is not only the product quality itself but also the product design and service behind it. One of the reasons why luxury goods are loved by 
people is that every product contains the designer's ideas and design, and every product comes from the designer's original design and the design team's efforts. For luxury goods, the best way to show designs on the Internet is through online shows. With the development of Internet networks, especially during the epidemic, want to return to the spotlight, the fashion show where the audience gathers is facing many obstacles. However, in such a special period, online shows are favored by various brands, live shows dominated by online media have become the main way for Dior to release new products. The online live show deepens the customer's sensory impression of the product through various forms, and the customer will also establish a deeper friendship with the brand based on the feeling of the fashion show. Luxury brands came later to these platforms, compared to other brands, due to their unique features, such as exclusivity and high status. However, luxury brand companies eventually realized that social media can have a positive impact on brands and that they needed to be part of this new world, and thus began to explore ways to exploit these new media [8].In July 2019, Dior's s online boutique officially landed in the Chinese market, selling a full range of products including handbags, high-end jewelry, beauty, and ready-to-wear. Previously, Dior has opened online boutiques in European countries and the United States.

Social media has become the method of statement in the 21 't century, enabling us to express our beliefs, ideas, and manner in a new way. This way of the message has also had a huge impact on corporations, where they have realized that without a correct plan and social media strategy they have no chance to stand out in the rapidly changing digital freedom. To guarantee a successful attendance on social media the companies need to consider different marketing theories so that they can boost their brand in different aspects [9]. Dior also attaches importance to the role of online and network communication media. Dior has 38.05 million fans on Instagram, 1.26 million fans on YouTube, and 7.278 million fans on Weibo (as of November 2021) [10-12]. Dior advertises on social media, publishes self-made promotional videos, and even online live shows. Luxury brands advertise on social media and make promotional videos not only for the current impact on sales but for the development of new customer groups. The younger generation of luxury brand consumers has become a trend, and the current young generation will be cultivated into the future. Brand target consumer groups to achieve long-term brand promotion.

\subsubsection{Weakness}

Compared with luxury brands, it can be found that FMCG brands actually have more price advantages in terms of online sales, and people often make faster decisions in the face of lower-priced products. The influence of price must play an important role in marketing. Because the price of luxury goods includes not only the product itself but also the service provided by the luxury industry to customers. Online shopping lacks the shopping experience of service. At the same time, when buying a product with a higher price, customers take longer to make the final decision and consider more factors. They may want to have a deeper understanding of the product before making a decision, such as offline experience. Therefore, when shopping online, the price of luxury goods is indeed an important factor affecting sales.

The online environment creates not only opportunities but also complications and challenges for the social media marketing process. Five main disadvantages need to be considered on social media marketing, which are: Time intensive, Trademark and Copyright Issues, Trust, Privacy and Security Issues, User-Generated Content (UGC), and negative feedback. Social media is interactive and successful, two-way exchanges take commitment. The nature of marketing changes in social networks, with the focus placed on establishing long-term relationships that can turn into more sales. Somebody has to be responsible to monitor each network, respond to comments, answer questions, and posting product information the customer deems valuable It is of the utmost importance for companies to protect their trademarks and copyrights when using social media to promote their brands and products. Companies should monitor their social media outlets as well as third-party social media platforms. Using social media to promote one's brand, products, or services can also implicate trust, privacy, and data security issues. Companies need to be aware of these issues and take appropriate measures to minimize their exposure to liability related to personal data collection, use, and 
maintenance [13]. Dior has shortcomings on social media in the above aspects. Online media means a large number of applications on the Internet, and it also means that there is a risk of fraud in both shopping platforms and online publicity. In addition, customer feedback on social platforms is also a problem for Dior. Dior rarely responds to customer comments on social media and lacks suggestions for improvements to customers on social media.

\subsubsection{Opportunity}

Social media strategic capability positively affects brand innovation and acts as a moderator between knowledge acquisition, market orientation, and brand innovation. It further enhances both types of market orientations in achieving brand innovation, suggesting that on social media, a customer's needs, both expressed and latent (or unexpressed), can be identified more comprehensively than that of the traditional setting [14]. Due to Dior's s high-end customization attributes, its target consumer group is not large. After accepting new media marketing, consumer groups can be further expanded, product positioning levels can be further subdivided, and more consumer needs can be met and established. And broaden other target markets. As one of the first brands to open online shopping boutiques in China, Dior has a keen sense of new media on the Internet. In addition to online shopping malls, mufti-platform official promotion and KOL's s mufti-faceted joint promotion have also increased Dior's fans. Dior has innovated online media shopping and promotion methods while retaining the traditional high-end design and offline store shopping experience, which will create greater business opportunities on the foundation of hundreds of years of fashion.

\subsubsection{Threaten}

More opportunity means more threat. Online social media promotion and online shopping have become trends in the transformation of modern shopping models, compared to luxury goods. Other types of brands have more advantages in the online shopping model. They have a wider range of online advertising, more refined product positioning, and younger audiences. As mentioned above, this is also Dior is working on development. Audience. In addition, for the luxury goods industry, not only Dior pays attention to the development of online promotion and shopping models, but other luxury brands with similar positioning have also taken action. Although Dior has an advantage in positioning brands, it faces the challenges of similar positioning brands. Catching up and other more different types of brands that have already occupied some limelight on the Internet, Dior still faces many threats.

\section{Result}

As a member of the French high-end luxury brand, Dior's s advanced online marketing methods and keen market direction make Dior stand out in the marketing of similar brands. In today's situation where luxury brand customers continue to be younger, Dior seizes marketing opportunities and makes new marketing strategies for new consumer groups in many aspects online. However, relatively speaking, luxury brands do not influence fast-moving consumer brands and fashion design brands to spread quickly. Because FMCG brands and fashion design brands tend to have a greater advantage on the Internet with their prices and novel designs. However, luxury brands already have a relatively stable customer base both offline and offline. The development of Dior's online shopping platform on social media is to continuously add new consumer groups. In addition, Dior has a relatively complete online marketing model. The brand's online fashion shows and the endorsements of popular celebrities are rarely available to non-luxury brands. Dior's long-term online development model will bring long-term profits and the most powerful publicity for the brand. 


\section{Discussion}

Through the above research of the article, it can conclude that fashion luxury brands can succeed in adapting and innovating online marketing strategies in the development of Internet media. This is basically in line with the viewpoint put forward in the article's introduction.

Dior should pay more attention to the customer's shopping experience on its official online platform. Make the classification of different types of products clearer and make shopping more convenient for customers who purchase with a purpose. And optimize the layout of the official website, enhance the visual effect, focus on the main product, and use exquisite advertising design to attract customers' attention. In addition, the official website can enhance manual customer service and artificial intelligence services, and enhance the online customer experience. In terms of online media promotion, Dior will increase our promotion efforts on social media with a large number of fans and carry out product promotion with multiple modes, innovations, and creativity. Increase the promotion of celebrity spokespersons to attract more fans.

\section{Conclusion}

This article is aimed at the rapid development of online media. Significant changes have taken place in global trade patterns, and the rapid rise of e-commerce and online media has affected the fashion and luxury brand industry. The research object of this article is the classic fashion luxury brand Dior, research on its marketing strategy under the development of its online model. The article introduces the detailed information of the brand, the strategies that have been made in Internet media, using consumer purchase intention and marketing mix theory. And the strength, weaknesses, opportunities, and threats of Dior's marketing strategies in Internet media through swot analysis. The article mentioned in the introduction that Dior's s online marketing strategy will have an advantage in the fashion luxury brand under the background of the development of Internet media, and it will expand new consumer groups and achieve success in marketing strategies. Through the above research in this article, it can conclude that our hypothesis is correct.

This article studies the transformation of luxury brand strategies that many people have overlooked under the development of Internet media. As a luxury brand with a completely different market positioning and a very different strategy from ordinary brands, Dior is used as the research object to explore how they respond to the development trend of Internet media. It fills up the vacancy in brand marketing strategies for different positioning. Suggestions and development model improvements for fashion luxury brands. However, the article is still limited in some aspects. The article is aimed at research in a global context, but it has not explored the situation that some people in certain regions have not yet adapted to the online shopping model. In addition, there is no research on whether the research of online luxury brands will affect the store services of offline fashion luxury brands. It even affects the brand's high-end positioning. In future research directions, Dior should strengthen the development model of a more reasonable online and offline sales model for fashion luxury brands, and how to maintain the brand's influence through a sales model that is more adapted to the development of the times while maintaining the high-end brand positioning.

\section{References}

[1] Younus, Sohail, Faiza Rasheed, and Anas Zia. "Identifying the factors affecting customer purchase intention." Global Journal of Management and Business Research (2015).

[2] Mirabi, Vahidreza, Hamid Akbariyeh, and Hamid Tahmasebifard. "A study of factors affecting on customers purchase intention." Journal of Multidisciplinary Engineering Science and Technology (JMEST) 2.1 (2015).

[3] POTURAK, Mersid, and Sumeja SOFTIC. "Influence of social media content on consumer purchase intention: Mediation effect of brand equity." Eurasian Journal of Business and Economics 12.23 (2019): $17-43$. 
[4] Išoraite, Margarita. "Marketing mix theoretical aspects." International Journal of ResearchGranthaalayah 4.6 (2016): 25-37.

[5] Goi, Chai Lee. "A review of marketing mix: 4Ps or more." International journal of marketing studies 1.1 (2009): 2-15.

[6] Kalyanam, Kirthi, and Shelby McIntyre. "The e-marketing mix: a contribution of the e-tailing wars." Journal of the academy of marketing science 30.4 (2002): 487-499.

[7] https://cn.fashionnetwork.com/news/dior-yu-zhan-yu-yong---qu-nian-shou-ru-ting-jin-50-yi-ou-yuan-jule-bu,1137379.html

[8] Brandão, Amélia, Eva Pinho, and Paula Rodrigues. "Antecedents and consequences of luxury brand engagement in social media." Spanish Journal of Marketing-ESIC (2019).

[9] Saravanakumar, Murugesan, and T. SuganthaLakshmi. "Social media marketing." Life science journal 9.4 (2012): 4444-4451.

[10] https://www.instagram.com/

[11] https://www.youtube.com/

[12] https://weibo.com/dior

[13] Nadaraja, Rubathee, and Rashad Yazdanifard. "Social media marketing: advantages and disadvantages." Center of Southern New Hempshire University (2013): 1-10.

[14] Nguyen, Bang, et al. "Brand innovation and social media: Knowledge acquisition from social media, market orientation, and the moderating role of social media strategic capability." Industrial Marketing Management 51 (2015): 11-25. 